\title{
A crise de eficiência da escola para além de seus muros: a influência dos capitais social, cultural e econômico no desempenho escolar em ciências
}

\author{
The school efficiency crisis beyond its walls: the social, cultural \\ and economic capital's influence in science scholar achievement
}

Eveline Borges Vilela-Ribeiro ${ }^{1}$. Anna Maria Canavarro Benite ${ }^{2}$

\begin{abstract}
Resumo: Avaliamos de que modo os capitais social, cultural e econômico dos estudantes do ensino secundário afetam, em escala global, o seu desempenho em ciências e teorizamos de que maneira esses resultados se relacionam à crise educacional tal como predita o modelo neoliberal. Utilizamos os resultados de ciências das avaliações realizadas pelo Programme for International Student Assessment (PISA) no ano de 2009 por diversos países e os relacionamos com índices de capitais cultural, social e econômico criados a partir de dados internacionais. Analisamos, no programa Statistica, de que maneira cada um dos capitais se relaciona ao desempenho dos países em ciências. Construímos, para isso, figuras que relacionam os capitais ao seu desempenho em ciências. Os resultados mostram que o capital econômico é fundamental ao bom desempenho em ciências; apenas o atrelamento entre todos os capitais (econômicos, sociais e culturais) é que pode fornecer, entretanto, uma explicação mais completa para os resultados.
\end{abstract}

Palavras-chave: Ensino médio. Ensino de ciências. Neoliberalismo. Desempenho escolar.

\begin{abstract}
We assess how the social, cultural and economic capital of the high school students on a global scale, affect their achievement in science and theorize how these results are related to the educational crisis as predicted by the neoliberal model. We use the results of science in the evaluations carried out by the Programme for International Student Assessment (PISA) in 2009 for many countries and relate to levels of cultural, social and economic capital raised from international data. We analyze how each relates to the performance of science in countries in Statistics program. For this, we build figures that relate capital to its performance in science. The results show that economic capital is key to good performance in science, however, only the linkage between all capitals (economic, social and cultural) can provide a more complete explanation of the results.
\end{abstract}

Keywords: High school. Science teaching. Neoliberalism. Students' achievement.

\footnotetext{
${ }^{1}$ Universidade Federal de Goiás (UFG), Jataí, GO, Brasil. E-mail: <eveline_vilela@ufg.br>.

${ }^{2}$ Universidade Federal de Goiás (UFG), Instituto de Química, Goiânia, GO, Brasil.
} 
Um questionamento que tem me orientado enquanto me constituo como pesquisadora em educação em ciências é: por que apesar de tantos progressos nas pesquisas em educação e em educação em ciências (melhorias no processo de ensino e aprendizagem, melhoria na formação inicial e continuada dos professores de ciências entre outros tantos) ainda não conseguimos soluções realmente efetivas aos problemas dentro do espaço escolar? Os alunos têm dificuldade em aprender ciências e sobre ciências, não se interessam pelas carreiras científicas e, recorrentemente, relatam seu desinteresse por elas (BLACK; ATKIN, 1996; HAAG, 2012; MALDANER, 2010).

Apesar de esse ser um questionamento individual, penso que muitas pessoas que conhecem e participam da realidade em sala de aula também o fazem. É decepcionante ao professor ver seus esforços frustrados durante o ano (desempenhos ruins dos estudantes, reprovação nas disciplinas, fracasso em exames), visto que o fracasso do estudante (em qualquer um dos níveis de ensino) representa também, de algum modo, o fracasso de seu professor.

Sou professora de um curso de Química no interior de Goiás. O número de estudantes em nosso curso reduziu, ao longo dos anos, drasticamente, ao ponto de existirem disciplinas com apenas um aluno matriculado. Ainda possuímos, além do baixo número de estudantes, àqueles com deficiências severas em formações anteriores, em exemplo, língua portuguesa e matemática básica, o que gera um novo problema: altos índices de reprovação nas disciplinas. E não temos conseguido, infelizmente, suprir essas deficiências. As disciplinas comuns do currículo não têm sido suficientes para sanar essas dificuldades. Esse problema que relato parece ser comum nos cursos de licenciatura de nosso país, bem como nas escolas de educação básica e representa um dos sintomas da crise na educação que assola o Brasil (FOUREZ, 2003).

Sob uma ótica neoliberal de organização da sociedade, esses problemas educacionais têm responsáveis diretos e indiretos e são explicados pelo termo "Crise de eficiência da escola". Essa crise refere-se à teórica incapacidade de o governo assegurar a qualidade e expansão da educação, uma vez que, apesar do aumento dos espaços educacionais, os países subdesenvolvidos ainda não conseguiram alcançar bons patamares de qualidade, ou seja, sob uma perspectiva neoliberal de educação não é possível existir, sob a égide pública, um ensino igualitário e que proporcione bons resultados (GENTILI, 2001). É uma crise de eficiência, haja vista que o Estado não a geri com eficácia; é de produtividade, porque o Estado utiliza meios mais caros para produzir um resultado que pode ser alcançado com menores custos.

Os culpados diretos seriam os sindicatos de professores e organizações que defendem os direitos das escolas públicas, bem como o governo que não consegue administrá-la com competência. Os indiretos seriam as escolas, os professores e os próprios estudantes por não terem o comprometimento necessário. Sob essa perspectiva, para sanar o imbróglio, é preciso remodelar a escola e todos os processos que a permeiam, deslocando a educação da esfera dos direitos sociais para a esfera do mercado (GENTILI, 1996). Quando a educação escolar passa a ser vista dessa maneira, iniciam-se processos de privatização na educação, redução dos salários dos professores, fechamento de escolas etc.

Essa reflexão faz-se necessária como uma tentativa de elucidar essa crise educacional em uma perspectiva mais ampla do que a fornecida pelo paradigma neoliberal. Entender a crise escolar perpassa, necessariamente, pela elucidação de todos os fatores que influenciam o cotidiano escolar. É necessário, embora conhecer todas as partes de um todo seja impossível, ao menos tentarmos desmistificá-las; ou seja, para elucidarmos o que acontece no interior do 
A crise de eficiência da escola para além de seus muros: ...

espaço escolar é preciso lançar mão de explicações complexas (MORIN, 2005). Para Morin, a complexidade trata de levar em conta, na ciência, as unidades e interações que fazem parte dela. O autor ainda coloca que:

\begin{abstract}
A visão não complexa das ciências humanas, das ciências sociais, considera que há uma realidade econômica de um lado, uma realidade psicológica de outro, uma realidade demográfica de outro etc. Acredita-se que estas categorias criadas pelas universidades sejam realidades, mas se esquece que no econômico há, por exemplo, as necessidades e os desejos humanos. Atrás do dinheiro há todo um mundo de paixões, há a psicologia humana. Mesmo dos fenômenos econômicos strictu sensu, atuam os fenômenos de multidão, os fenômenos ditos de pânico [...] (MORIN, 2005, p. 69).
\end{abstract}

Falar, portanto, em crise escolar para além de seu espaço significa entender que a escola é multifatorialmente influenciada por fatores intrínsecos a ela, mas também por fatores externos, por exemplo: o nível cultural da família com quem o estudante convive, a maneira como os responsáveis o ajudam nos estudos, a excelência do estabelecimento de ensino por ele frequentada entre outros inúmeros itens que podem influenciá-lo o desempenho escolar (ALVES, 2010; ALVES, SOARES, 2009; BARROS et al., 2001; DUNCAN, MORRIS, RODRIGUES, 2011). Utilizaremos, para análise neste trabalho, a teoria dos capitais de Bourdieu (2011) para avaliar se os capitais social, cultural e econômico dos estudantes do ensino secundário afetam o seu desempenho em ciências em um contexto global e analisar de que maneira esses fatores podem fornecer subsídios para acrescentar fatores à explicação dessa crise educacional predita pelo modelo neoliberal.

\title{
Quais capitais?
}

A conceituação de Capital é complexa, mas Bourdieu (2011) o define como:

[...] is accumulated labor (in its materialized form or its incorporated, enbodied form) which, when appropriated on a private, i.e, exclusive basis by agents or groups of agents, enables them to appropriated social energy in the form of reified or living labor. (BOURDIEU, 2011, p. 81).

É possível, pois, acumular capital, produzir lucro por meio dele e reproduzi-lo. A forma de distribuição do capital e seus subtipos representam, para o autor, a estrutura social do momento histórico ao qual pertencem. Ele enumera três tipos de "disfarces" (BOURDIEU, 2011) para os capitais: econômico, social e cultural.

Falamos, resumidamente, que o capital econômico é representado por diferentes fatores de produção e bens econômicos, podendo ser acumulado, reproduzido e ampliado por meio de estratégias específicas. É o conjunto dos bens materiais e econômicos do indivíduo e que interfere diretamente nas percepções desse sobre o mundo, já que é o capital econômico que determinará os demais tipos de capitais. (BOURDIEU; PASSERON, 2012). 
Já o capital cultural tem relação com a presença de determinadas atividades, conhecimentos, informações e gostos obtidos pelo indivíduo no que diz respeito ao conhecimento do mundo (SILVA, 1995). É o conhecimento obtido pela leitura de livros, visitas a instituições culturais, cinemas, viagens entre outras formas. Ele se apresenta sob três formas principais: incorporado, objetivado e institucionalizado. O capital cultural incorporado diz respeito às formas de disposições duradouras da mente e do corpo, são as capacidades culturais transmitidas socialmente, enquanto o capital cultural objetivado tem relação com os bens culturais (obras de arte, peças, instrumentos, dentre outros), já o capital cultural institucionalizado apresenta-se sob a forma dos títulos e diplomas adquiridos. A "hereditariedade" do capital cultural é o processo de transmissão mais eficaz para perpetuação de seus bens, uma vez que é possível adquiri-lo via convívio familiar e social, bem como os bens inerentes ao capital cultural. Insere-se aqui, então, o conceito de capital social.

O capital social representa o conjunto das relações sociais que um indivíduo possui; é tudo aquilo que se relaciona aos acessos sociais e à rede de contatos - familiares ou não (BOURDIEU; PASSERON, 2012). Tem a ver com interação do agente a um grupo específico ou participação em uma rede de contatos. Para se incrementar, por conseguinte, esse tipo de capital é preciso que haja estratégias de investimento, transformando as relações contingentes em relações profícuas de troca de saberes e experiências (BOURDIEU, 2011). É, assim, necessariamente um capital que é obtido por meios das interações:

In other words, the network of relationships is the product of investment strategies, individual or collective, consciously or unconsciously aimed at establishing or reproducing relationships that are directly usable in the short or long therm, i.e., at transforming contingent relations, such as those neighborhood, the workplace, or even kinship, into relations that are at once necessary and elective, implying durable obligations subjectively felt $[\ldots]$ or institutionally guaranteed (rights). This is done trough the alchemy of consecration, the symbolic constitution produced by social institution (institution as a relative - brother, sister, cousin, etc - or a knight, an heir, an elder, etc.) and endlessly reproduced in and through the exchange [...] which it encourages and which presupposes and produces mutual knowledge and recognition. (BOURDIEU, 2011, p. 87).

Dois elementos constituem o capital social: (i) as redes de relações sociais, e (ii) a quantidade e a qualidade desse recurso do grupo a que pertence. As redes de relações importam, porque são elas as responsáveis pelas trocas materiais e simbólicas entre os agentes de um mesmo grupo. Quanto à quantidade e à qualidade, elas dependerão do volume de capital (das variadas formas) que o agente pode mobilizar por meio do convívio. Assim, quanto maior for a qualidade dos capitais que os diferentes agentes de um determinado campo possuem, maior capital social acumulado eles serão capazes de possuir (BOURDIEU, 1998). São relevantes, do mesmo modo, aqui, a estrutura familiar e os aspectos envolvidos em sua constituição - por exemplo: o tamanho, a composição familiar e os modos como essas relações se operacionalizam. O ambiente social em que a pessoa está inserida o influencia por meio das possibilidades de acessos cognitivos - mais ou menos complexos - que são capazes de fornecer subsídios 
A crise de eficiência da escola para além de seus muros: ...

instrumentais para que o agente - em maior ou menor escala - instrumentalize-se.

O capital econômico é a fonte para os capitais social e cultural, mas é o capital social que pode ser transformado em capital cultural e econômico no decorrer do tempo. Aos agentes que detêm mais capital social, os capitais econômico e cultural podem ser mais proeminentes (AQUINO, 2000). De maneira mais ampla, esses três diferentes capitais relacionam-se, consequentemente, entre si e exercem influência na formação do indivíduo.

\section{A estratégia de análise ${ }^{3}$}

Utilizamos, para realizarmos as análises, os resultados de ciências das avaliações realizadas pelo Programme for International Student Assessment (PISA) no ano de 2009 por diversos países (Quadro 1), o questionário socioeconômico que os estudantes responderam no PISA e no banco de dados internacionais. Para compor os capitais, as variáveis escolhidas foram aquelas que melhor dialogaram com o nosso referencial teórico e que estavam disponíveis nesses bancos de dados utilizados. Os índices para cada um dos capitais são crescentes, isto é, quanto maior o índice do capital, mais o país o possui.

Quadro 1. Países usados na análise global

\begin{tabular}{|l|l|l|l|l|l|l|l|}
\hline \multicolumn{2}{|c|}{ Nome do país } & \multicolumn{2}{|c|}{ Nome do país } & \multicolumn{3}{c|}{ Nome do país } & \multicolumn{2}{|l|}{ Nome do país } \\
\hline 1 & Alemanha & 15 & Croácia & 29 & Irlanda & 43 & Portugal \\
\hline 2 & Argentina & 16 & Dinamarca & 30 & Islândia & 44 & Reino Unido \\
\hline 3 & Austrália & 17 & Dubai & 31 & Israel & 45 & República Tcheca \\
\hline 4 & Áustria & 18 & Eslováquia & 32 & Itália & 46 & Romênia \\
\hline 5 & Bélgica & 19 & Eslovênia & 33 & Japão & 47 & Rússia \\
\hline 6 & Brasil & 20 & Espanha & 34 & Liechtenstein & 48 & Sérvia \\
\hline 7 & Bulgária & 21 & Estados Unidos & 35 & Lituânia & 49 & Singapura \\
\hline 8 & Canadá & 22 & Finlândia & 36 & Macao & 50 & Suécia \\
\hline 9 & Catar & 23 & França & 37 & México & 51 & Suiça \\
\hline 10 & Cazaquistão & 24 & Grécia & 38 & Noruega & 52 & Tailândia \\
\hline 11 & Chile & 25 & Holanda & 39 & Nova Zelândia & 53 & Tunísia \\
\hline 12 & China (Xangai) & 26 & Hong Kong & 40 & Panamá & 54 & Turquia \\
\hline 13 & Colômbia & 27 & Hungria & 41 & Peru & 55 & Uruguai \\
\hline 14 & Coréia & 28 & Indonésia & 42 & Polônia & & \\
\hline
\end{tabular}

Fonte: elaborado pelas autoras.

\footnotetext{
${ }^{3}$ Os resultados apresentados nesse trabalho, bem como o método utilizado consistem em uma simplificação das análises realizadas. A ideia é que professores e pesquisadores visualizem outros fatores que podem influenciar a educação, além dos que tradicionalmente pesquisamos em educação em ciências. Os formalismos matemáticos utilizados para a análise, bem como a discussão dos resultados sob um viés estatístico estão disponíveis no link: <https://www.dropbox.com/s/2amnxkv8pmq8sut/A\%20crise \%20de\%20eficiencia_2016.pdf?dl=0>. Acesso em: 23 mar. 2017.
} 
Por meio do questionário socioeconômico do PISA definimos variáveis que compuseram os capitais social e cultural dos países (Quadro 2).

O capital econômico de cada país foi definido pelo que denominamos de Produto Interno Bruto (PIB) por estudante (PIBpe) (AMARAL, 2013). O PIBpe é um índice que leva em conta não apenas a porcentagem do PIB investido em educação, mas sim que investimento representa levando em conta o valor do PIB em cada país e a quantidade de pessoas em idade escolar. É uma métrica que permite estimar mais detalhadamente o investimento de cada país na educação. Obtivemos os dados de PIB dos países pesquisados e a porcentagem que é investida em educação nesses mesmos países junto aos bancos de dados da Agência de Inteligência Central (CENTRAL INTELLIGENCE AGENCY, 2009). Obtivemos, além disso, os dados do tamanho populacional em idade escolar (0-24 anos) no banco de dados das Nações Unidas (UNITED NATIONS, 2009). A partir desses dados, calculamos o capital econômico que os países investem em educação.

Quadro 2. Variáveis que constituíram os capitais social e cultural ${ }^{4}$

\begin{tabular}{|l|l|}
\hline \multicolumn{1}{|c|}{ Capital social } & \multicolumn{1}{c|}{ Capital cultural } \\
\hline $\begin{array}{l}\text { O estudante mora na casa com mãe (incluindo } \\
\text { madrasta) }\end{array}$ & O estudante possui uma mesa para estudar \\
\hline $\begin{array}{l}\text { O estudante mora na casa com pai (incluindo } \\
\text { padrasto) }\end{array}$ & O estudante possui computador próprio \\
\hline O estudante mora na casa com irmão & O estudante possui livros de literatura em casa \\
\hline O estudante mora na casa com irmã & O estudante possui livros para ajudar na escola \\
\hline O estudante mora na casa com avôs & $\begin{array}{l}\text { O estudante possui biblioteca com mais de 25 } \\
\text { livros em casa }\end{array}$ \\
\hline O estudante mora com outras pessoas & O estudante lê pelo menos meia hora por dia \\
\cline { 2 - 2 } & Nível de escolaridade do pai \\
\cline { 2 - 2 } & Nível de escolaridade da mãe \\
\hline
\end{tabular}

Fonte: OECD (2010a, 2010b).

Analisamos de que maneira cada um dos capitais se relaciona ao desempenho dos países em ciências (por meio da nota em ciências do PISA 2009) no programa Statistica. Construímos, para isso, figuras (Capital Econômico X Desempenho - Figura 1; Capital Cultural x Desempenho - Figura 3; Capital Social x Desempenho - Figura 4) que relacionam cada um dos capitais (no eixo $\mathrm{x}$ - o horizontal) ao seu desempenho em ciências (no eixo y - o vertical)

\footnotetext{
${ }^{4}$ Como esclarecemos anteriormente, as variáveis utilizadas foram aquelas as quais tínhamos acesso e que melhor se adequavam ao nosso escopo teórico. Desse modo, as variáveis que compõem o Capital social estão restritas às relações sociais familiares porque é o indicador que o Questionário Socioeconômico possuía. Embora exista um Questionário aplicado diretamente aos pais na prova do PISA, não existiam, até a data da realização da pesquisa, dados suficientes para serem inseridos como indicadores do Capital Social e Cultural dos estudantes. São, por isso, apenas esses os indicadores selecionados para comporem os capitais.
} 
no programa CorelDraw. Uma nuvem de pontos foi formada, sendo que cada ponto relaciona o índice do país para um dos capitais ao seu desempenho em ciências. Avaliamos as tendências observadas em cada umas das figuras.

Avaliamos também, além disso, o quanto cada um dos capitais influencia o outro e o quanto eles influenciam, individualmente, o desempenho dos países em ciências. Os resultados são mostrados em forma de figura (Figura 5) que indicam, em porcentagem, o quanto cada um dos capitais está influenciando o outro, bem como o quanto cada um deles influencia o desempenho do país em ciências.

\section{Resultados e Discussão}

A Figura 1 apresenta os resultados encontrados para a relação entre o capital econômico de cada país e o desempenho médio do país em ciências. Três tendências principais podem ser observadas na relação, descritas na Figura 1 pelos números 1, 2 e 3.

Figura 1. Relação entre o capital econômico e o desempenho em ciências

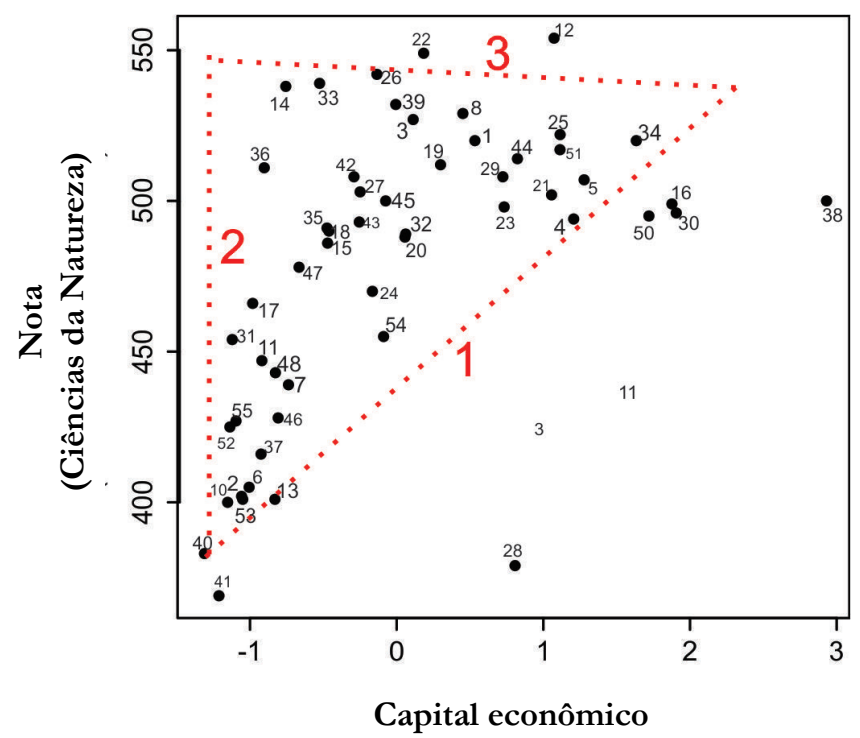

Nota: os números em preto correspondem ao número do país de acordo com o Quadro 1. Fonte: elaborado pelas autoras.

A primeira tendência (marcada em 1 na Figura 1) mostra uma relação que é comumente esperada: quanto maior o capital econômico do país, maior a média do desempenho dos estudantes em ciências. 
A segunda tendência (marcada em 2 na figura 1) indica que países com menor capital econômico possuem desempenhos em ciências tanto altos quanto baixos. Observe que a partir do capital econômico próximo à média (Figura 2), que equivale a aproximadamente a $\$ 4.400$ (representado no cruzamento dos eixos x e y), o desempenho dos países no PISA é sempre maior que 450 pontos (exceto Catar). Há, abaixo desse valor de capital econômico, desempenhos mais heterogêneos (maiores e menores que 450 pontos).

A terceira tendência (marcada em 3 na Figura 1) mostra uma fraca relação negativa entre o desempenho dos países em ciências e o capital econômico, ou seja, quanto maior o capital econômico pior será desempenho desse país em ciências. Essa relação pode ser explicada, contudo, pelo número de países investigados ser pequeno e tendenciar a relação.

Figura 2. Relação entre o capital econômico e o desempenho em ciências, mostrando as linhas representativas das médias

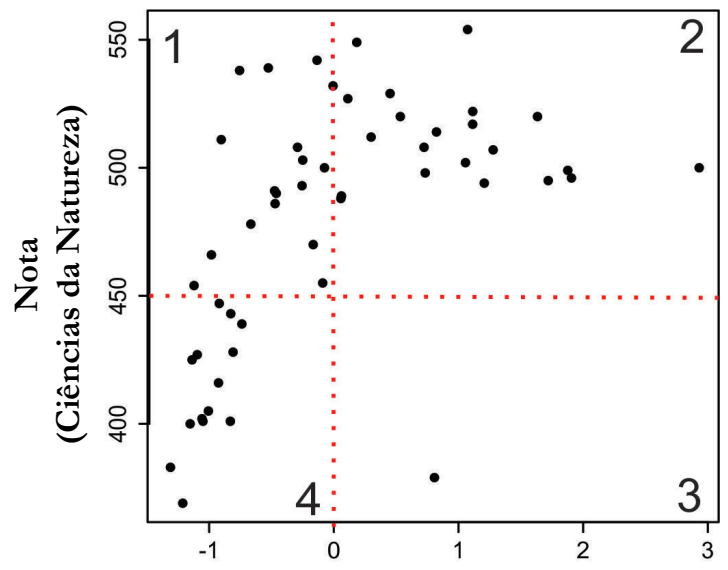

Capital econômico

Fonte: elaborada pelas autoras.

Podemos observar, além dessas interferências, ainda na relação entre o capital econômico e o desempenho dos países em ciências que nos países em que há capital econômico acima da média (marcado como 0 no eixo do Capital econômico), os países possuem apenas desempenho em ciências maior que a média de nota da amostra (450 pontos), exceto Catar. Com relação a Figura 2, a região 1 mostra a seguinte relação: países que investem abaixo da média e possuem desempenhos em ciências acima da média; a região 2: países que investem acima da média e possuem desempenho em ciências maior que a média; a região 3: um único caso, do Catar, e mostra a região dos países que investem acima da média e possuem desempenho em ciências abaixo da média e; a região 4: países que investem menos que a média e também possuem um desempenho abaixo da média. 
Amaral (2015) mostra um padrão relacional semelhante ao proposto nos resultados mostrados nas Figura 1 e 2 . O autor mostra a existência de quatro regiões distintas em uma nuvem de pontos da relação entre o investimento em educação e o desempenho dos estudantes no PISA, sendo elas: (a) países que investem mais do que a média de investimento e têm nota maior que a média PISA; (b) países que investem menos do que a média e têm nota maior que a média PISA; (c) países que investem menos do que a média e têm nota menor que a média PISA, e; (d) países que investem mais do que a média e têm nota menor que a média PISA. $\mathrm{O}$ autor argumenta, narrativamente, que o valor de $\$ 6.000$ por estudante em um país pode redundar em seu melhor desempenho no teste e que menor investimento pode acarretar uma diminuição do resultado do PISA. Ou seja, embora o valor apresentado por ele seja diferente do valor estimado por nós, em ambos os casos é possível teorizar uma relação entre o capital econômico e o desempenho escolar dos países na prova PISA. Existe, pois, um capital econômico mínimo necessário a ser aplicado na educação para que ela redunde em desempenhos escolares melhores que a média.

Não estando indiferentes a outros fatores que afetam o desempenho escolar em ciências dos estudantes, a avaliação dos demais capitais (social e cultural) torna-se importante. A relação entre o capital cultural e o desempenho dos países em ciências é mostrada na Figura 3 e entre o capital social e o desempenho dos países em ciências na Figura 4.

Figura 3. Relação entre o capital cultural e o desempenho em ciências

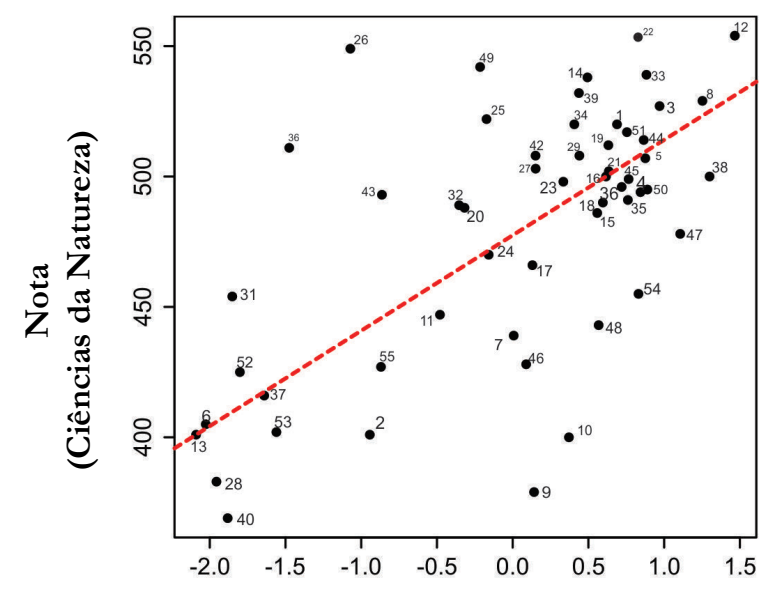

\section{Capital cultural}

Nota: os números em preto correspondem ao número do país de acordo com o Quadro 1.

Fonte: elaborada pelas autoras. 
Figura 4. Relação entre o capital social e o desempenho em ciências

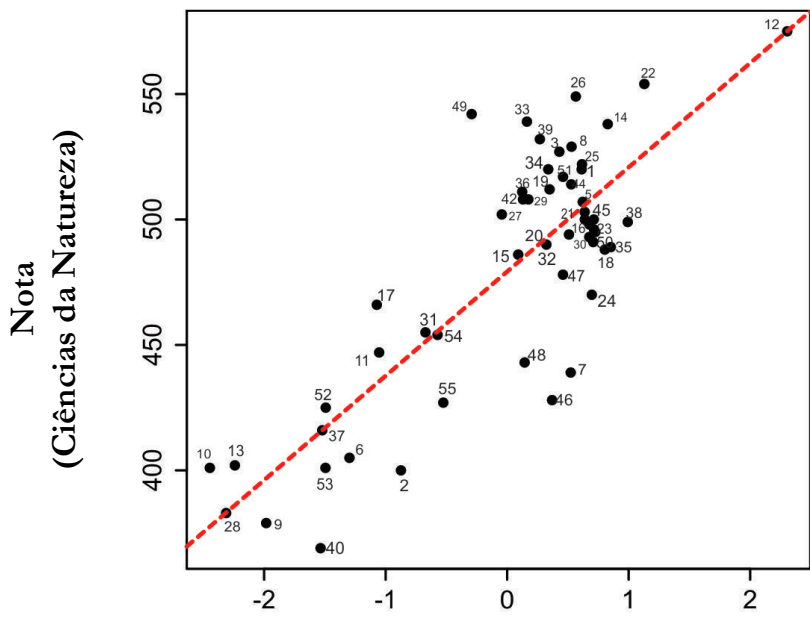

Capital social

Nota: Os números em preto correspondem ao número do país de acordo com o Quadro 1.

Fonte: elaborada pelas autoras.

Diferentemente da relação mostrada na Figura 1, em ambos os casos (Figuras 3 e 4), a relação entre os capitais e o desempenho médio em ciências dos estudantes é positiva e não há presença da relação exposta pela reta vertical da Figura 1. Maiores capitais cultural e social indicam, portanto, melhores desempenhos em ciências.

Os indicadores utilizados para determinar, em nossa análise, o capital social médio do país, têm relação com a estrutura familiar do estudante. Para a construção desse indicador, levamos em conta que cada uma das variáveis possuía diferentes relações com o desempenho dos estudantes. Por exemplo, países em que maior parte dos estudantes moram com pai (ou padrasto) e mãe (ou madrasta) possuem melhor desempenho em ciências do que aqueles países em que a maioria dos estudantes moram com avós, outras pessoas ou parentes (Figura 3). A medida do indicador de capital social incluiu, desse modo, não o fato de os estudantes morarem com avós, outras pessoas ou parentes, mas sim o inverso dessa realidade, uma vez que a primeira situação é uma relação negativa. Ou seja, os países cuja maioria dos estudantes não mora com os pais têm pior desempenho em ciências do que aqueles países cuja maioria mora (Figura 3). Acreditamos que, a importância do convívio familiar está, nesse caso, na manutenção de relações bem estabelecidas e sistematizadas que facilitam o processo de socialização dos estudantes e, assim sendo, sua enculturação científica:

[a família] é quem insere o homem em sua classe e, assim, na sociedade; adverte: o trabalho, a classe e a sociedade são interiorizados pela criança, por intermédio da apreensão que deles fazem seus próprios pais, a partir de suas particulares condições de trabalho. Tais interiorizações - e de vários 
A crise de eficiência da escola para além de seus muros: ...

outros aspectos da vida social - muito antes de derivarem da experiência pessoal primeira derivam, portanto, inicialmente, da experiência de outrem: dos mediadores. E, sobretudo, não apenas tudo isso se passa e é transmitido no interior de uma família particular, mas há uma história de como o grupo familiar vive, de geração em geração, a vida social: essa história é transmitida e apreendida, evidentemente, pelas novas gerações, objetiva e subjetivamente. (GOMES, 1992, p. 93-94).

Países com estudantes que possuem, portanto, melhores relações sociais estabelecidas em casa conseguem, com capital social de mais qualidade, que eles interiorizem a cultura escolar com mais eficiência, uma vez que aprenderam a deter, ao longo da vida, os mecanismos culturais utilizados na escola (Figura 3).

O capital social, enquanto indicador das relações que as pessoas mantêm umas com as outras exerce, pois, influência na constituição do babitus do sujeito. As pessoas que convivem, no decorrer de suas vidas, com aqueles que detêm o habitus das classes sociais mais elevadas e que entram em contato com os conhecimentos que foram socialmente reconhecidos, terão, como saberes escolares, melhor desempenho em ciências.

Quanto ao índice de capital cultural dos países, nossa análise indica que os países com pais mais escolarizados, casas com ambiente mais adequado aos estudos, computador individual para o estudante (em resumo, países que apresentem maior rendimento cultural) possuem um melhor desempenho em ciências do que aqueles com baixo índice cultural (Figura 4).

Tendo-se em vista essas relações, podemos analisá-las à luz do conceito de habitus, que não foi pensado por Bourdieu como um conceito isolado, mas sim de uma maneira que interconecta todos os capitais. O capital cultural entra aqui então com um importante papel de explicação do desempenho dos estudantes em ciências que são detentores de diferentes capitais sociais. Diferenças de capitais econômicos entre os países podem redundar em diversidade nos capitais social e cultural. Capitais sociais heterogêneos estão relacionados, normalmente, a diferentes capitais culturais e, consequentemente, a diferentes desempenhos escolares (BOURDIEU, 2007); em nosso caso, diferentes desempenhos em ciências pelos países.

Em relação à influência que os capitais podem ter entre si e a influência específica isolada no desempenho dos estudantes em ciências, observamos as relações expostas na Figura 5. Aproximadamente $70 \%$ do desempenho escolar dos países em ciências é explicado pelos capitais. Quase 50\% dessa relação é explicada, entretanto, pela interação entre os capitais e apenas a interação entre os três capitais já explica 35,6\% da variância no desempenho. Existir esse grande valor de influência entre os capitais significa, logo, que eles explicam a mesma coisa.

O modelo de nossa análise que descreve a relação entre os capitais e o desempenho escolar pode ser resumido da seguinte maneira: todos os capitais afetam uns aos outros, mas quando há controle de um dos capitais, o efeito isolado de cada um no desempenho é muito pequeno e o que melhor explica essa relação é a interação entre todos os capitais, ou seja, um indicador que englobe todos os capitais é adequado para estabelecer as relações entre os capitais e o desempenho dos países em ciências.

O modelo evidencia a complexidade do estudo dos fenômenos sociais ligados à educação, já que as relações estabelecidas entre os diferentes capitais são tão complexas que se sobrepõem umas às outras, retratando o conceito de habitus de Bordieu. 
Figura 5. Efeito específico e efeito combinado dos capitais cultural, econômico e social sobre o desempenho dos países em ciências

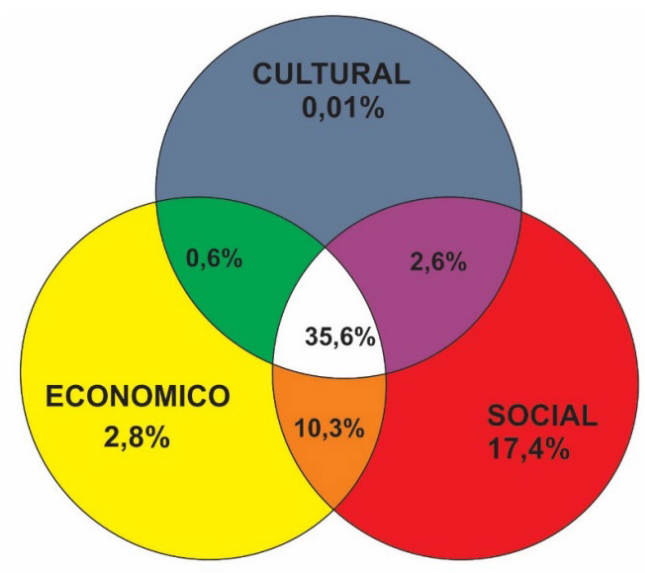

Efeito total $=69,3 \%$

Fonte: elaborada pelas autoras.

As desigualdades escolares constituem-se, sob essa ótica, como reflexos das desigualdades social e econômica. Rumberger (2010, p. 253) concluiu que:

Students from privileged background complete more schooling and earn higher wages than students from disadvantaged backgrounds. And human capital variables - education, cognitive skills and noncognitive skills - only explain some of these relationships. This suggests, for example, that even if students from disadvantaged backgrounds acquire the same level of cognitive skills by the end of eighth grade and have the same desire to attend college, they are still less likely to do so than students from a privileged background.

Essas análises ratificam o fato de que os privilégios social, cultural e econômico exercem influência sobre o desempenho escolar dos estudantes em ciências, uma vez que as oportunidades de acesso a bens culturais e educacionais têm relação com os capitais que suas famílias possuem ou têm acesso. Para Bourdieu e Passeron (2012), ignorar a influência da origem social sobre o êxito escolar apresenta-se como uma espécie de negligência. Segundo os autores, "isso seria ignorar a lógica específica segundo a qual as vantagens e as desvantagens sociais se retraduzem, progressivamente, ao curso das seleções sucessivas, em vantagens ou desvantagens escolares." (BOURDIEU; PASSERON, 2012, p. 196). 
A crise de eficiência da escola para além de seus muros: ...

Inferimos ainda que os capitais social e cultural conseguem explicar, também, não obstante, o porquê de pouco dinheiro ser investido em educação, de alguns países conseguirem alcançar, em média, desempenhos razoáveis quando comparados a outros. Os países que oferecem, de alguma maneira, acesso aos capitais, apesar de possuírem comparativamente menor capital econômico investido em educação, saem-se tão bem quanto os outros com maior investimento.

Carnoy, Gove e Marshall (2007) analisam os bons resultados de Cuba em testes de linguagem, matemática e ciência, comparando com as realidades brasileira e chilena e mostra que, apesar de o Brasil e de o Chile possuírem melhores indicadores socioeconômicos que Cuba, os estudantes cubanos se saem melhor que os brasileiros e os chilenos. $\mathrm{O}$ autor atribui isso ao que ele denomina de "state-generated social capital" (capital social gerado pelo estado), que são as políticas estatais desenvolvidas pelo governo e que afetam o capital social das crianças, por meio da geração de um ambiente educacional mais estimulante e iniciativas que beneficiam sua aprendizagem. Ele enumera uma série de fatores que justificam o porquê de crianças com baixos níveis sociais e econômicos terem desempenhos tão bons quanto os com esses índices elevados, mas o que tiramos de lição de seu estudo é que se o Estado for incompetente na administração escolar, não houverem professores qualificados, bem formados e valorizados e investimento nas questões sociais e culturais da população, o insucesso escolar entre a população mais pobre continuará sendo verdade.

É, nesse sentido, papel essencial dos governos possibilitarem e estimularem o acesso da população aos bens culturais e sociais, uma vez que esse acesso pode ser capaz de neutralizar - ou até mesmo driblar - os mecanismos de seleção social. Argentina e Coréia tem, por exemplo, aproximadamente o mesmo capital econômico; a Argentina alcançou, apesar disso, a média PISA de 401, enquanto Coréia de 538. Quando observamos, contudo, seus indicadores de capitais cultural e social, a Coréia possui índices de capitais cultural e social acima da média, enquanto na Argentina os índices estão abaixo da média.

\section{Considerações finais}

O que podemos afirmar, com base no exposto, é que o investimento em educação é fundamental para a existência de boas condições educacionais. Apenas o atrelamento entre todos os fatores (econômicos, sociais e culturais) é que pode fornecer, entretanto, um resultado educacional melhor para a interpretação dos resultados nesse contexto global. Pelas análises é possível inferir, portanto, que os fatores externos às escolas se mostram preponderantes ao avaliarmos o que influencia o desempenho escolar em ciências de estudantes (aproximadamente $70 \%$ do desempenho em ciências dos países pode ser explicado pelos fatores sociais, culturais e econômicos). Essas análises nos fornecem subsídios para afirmarmos que a educação formal depende da união entre fatores sociais, culturais e econômicos e que ela não é unidirecionalmente influenciada, como por exemplo, apenas por uma crise de produtividade educacional com raízes econômicas.

Não olhamos, no entanto, acriticamente para a ideia de que os capitais cultural e social são relevantes no desempenho escolar dos alunos em ciências. É preciso citar aqui que o próprio acesso aos capitais cultural e social são reflexos das desigualdades geradas pelo modo de produção vigente e constituem-se, por conseguinte, privilégios. O que acontece na escola nada mais é, 
então, do que a reprodução em microescala do que acontece na sociedade. (FRIGOTTO, 1996).

Quando a escola e os professores decidem trabalhar, contudo, de forma metódica e sistemática, mobilizando os meios disponíveis, proporcionando o contato com leituras críticas da realidade, oferecendo oportunidades educacionais estimulantes, ela pode ser capaz de proporcionar uma outra alternativa social e não apenas ser reprodutora das desigualdades. Para Bourdieu e Darbel (2007) a escola poderia ocupar outro papel na sociedade se conseguisse diminuir as distâncias dos capitais social e cultural entre os diferentes estratos sociais:

A escola, cuja função específica consiste em desenvolver ou criar as disposições que fazem o homem culto e constituem o suporte de uma prática duradoura e intensa, ao mesmo tempo, de forma quantitativa e qualitativa, poderia compensar (pelo menos parcialmente) a desvantagem inicial daqueles que, em seu meio familiar, não encontram a incitação da prática cultural, nem a familiaridade com as obras, pressuposta por todo discurso pedagógico sobre as obras, com a condição somente de que ela utilize todos os meios disponíveis para quebrar o encadeamento circular de processos cumulativos ao qual está condenada qualquer ação de educação cultural. (BOURDIEU; DARBEL, 2007, p. 108).

Para aquelas pessoas oriundas de estratos da população em que não há acesso a bens culturais legitimados historicamente pela sociedade ou convívio social que permita o conhecimento desses bens, a escola adquire papel fundamental de transmissão da herança cultural. Não basta, desta forma, compreender a crise escolar em termos econômicos e de que maneira a escola pode ser mais rentável, é preciso entender a escola como parte de um todo social em que as condições sociais, psicológicas, familiares e culturais traduzem-se em resultados educacionais.

A crise de eficiência da escola pode ser interpretada, por isso, como um reflexo da crise da sociedade capitalista como um todo. A escola está em crise, já que não conseguimos alfabetizar cientificamente nossos alunos e a literatura nos mostra que isso não é um problema apenas brasileiro. A crise da escola não é, não obstante, meramente uma crise de eficiência, é uma crise ideológica, assim como as demais crises que a sociedade atual enfrenta.

\section{Referências}

ALVES, F. Escolhas familiares, estratificação educacional e desempenho escolar: quais relações? Dados, Rio de Janeiro, v. 53, n. 2, p. 447-468, 2010. Disponível em: < http:// dx.doi.org/10.1590/S0011-52582010000200006>. Acesso em: 23 mar. 2017.

ALVES, M. T. G.; SOARES, J. F. Medidas de nível socioeconômico em pesquisas sociais: uma aplicação aos dados de uma pesquisa educacional. Opinião Pública, Campinas, v. 15, n. 1, p. 1-30, 2009. Disponível em: <http://dx.doi.org/10.1590/S010462762009000100001>. Acesso em: 23 mar. 2017. 
A crise de eficiência da escola para além de seus muros: ...

AMARAL, N. C. Os 10\% do PIB como promotor da qualidade da educação: uma análise considerando os resultados do PISA e os valores aplicados por estudante em diversos países. In: GOUVEIA, A. B.; REZENDE PINTO, J. M.; FERNANDES, M. D. E. (Org.). Financiamento da educação no Brasil: os desafios de gastar 10\% do PIB em dez anos... Campo Grande: Oeste, 2015. v. 1, p. 61-82.

. O novo PNE e o financiamento da educação no Brasil: os recursos como um percentual do PIB. In: PINO, I. R.; ZAN, D. D. P. (Org.). Plano Nacional de Educação (PNE): questões desafiadoras e embates emblemáticos. Brasília: Inep, 2013. p. 85-102. Disponível em: < http://www.publicacoes.inep.gov.br/portal/download/756>. Acesso em: 23 mar. 2017.

AQUINO, J. A. As teorias da ação social de Coleman e Bourdieu. Humanidades e Ciências Sociais, Fortaleza, v. 2, n. 2, p. 17-30, 2000.

BARROS, R. P. et al. Determinantes do desempenho educacional no Brasil. Pesquisa e Planejamento Econômico, Rio de Janeiro, v. 31, n. 1, p. 1-42, 2001.

BLACK, P.; ATKIN, J. M. Changing the subject, innovations in science, mathematics and technology education. London: Routledge, 1996.

BOURDIEU, P. A economia das trocas simbólicas. São Paulo: Perspectiva, 2007.

. Escritos de educação. Petrópolis: Vozes, 1998.

. The forms of capital. In: SZEMAN, I.; KAPOSY, T. Cultural theory: an anthology. Oxford: Wiley-Blackwell, 2011. p. 81-93.

BOURDIEU, P.; DARBEL, A. O amor pela arte: os museus de arte na Europa e seu público. São Paulo: Edusp, 2007.

BOURDIEU, P.; PASSERON, J. C. A reprodução: elementos para uma teoria do sistema de ensino. Rio de Janeiro: Vozes, 2012.

CARNOY, M.; GOVE, A. K.; MARSHALL, J. H. Cuba's academic advantage: why students in Cuba do better in school. California: Standford University Press, 2007.

CENTRAL INTELLIGENCE AGENCY. The world factbook 2009. Washington: CIA, 2009.

DUNCAN, G. J.; MORRIS, P. A.; RODRIGUES, C. Does money really matter?: estimating impacts of family income on young children's achievement with data from random-

assignment experiments. Developmental Psycology, Washington, v. 47, n. 5, p. 1263-1279, 2011.

FRIGOTTTO, G. Educação e a crise do capitalismo real. São Paulo: Cortez, 1996.

FOUREZ, G. Crise no ensino de ciências. Investigações em Ensino de Ciências, Porto Alegre, v. 8, n. 2, p. 109-123, 2003. Disponível em: < http://www.if.ufrgs.br/ienci/artigos/ Artigo_ID99/v8_n2_a2003.pdf >. Acesso em: 24 mar. 2017.

GENTILI, P. A falsificação do consenso: simulacro e imposição na reforma educacional. Petrópolis: Vozes, 2001. 
GENTILI, P. Neoliberalismo e educação: manual do usuário. In: SILVA, T. T. S.;

GENTILI, P. (Org.). Escola S. A.: quem ganha e quem perde no mercado educacional do neoliberalismo. Brasília: CNTE, 1996. p. 9-49.

GOMES, J. V. Família e socialização. Psicologia USP, São Paulo, v. 3, n. 1-2, p. 93-105, 1992.

HAAG, C. O que você não quer ser quando crescer? Pesquisa Fapesp, São Paulo, n. 192, p. 82-85, 2012. Disponível em: <http://revistapesquisa.fapesp.br/wp-content/ uploads/2012/02/082-085_PercepcaoCiencia_192Corr.pdf?94c086>. Acesso em: 24 mar. 2017.

MALDANER, O. A. Prefácio. In: ECHEVERRIA, A. R.; ZANON, L. B. Formação superior em química no Brasil: práticas e fundamentos curriculares. Ijuí: Unijuí, 2010. p. $9-16$.

MORIN, E. Introdução ao pensamento complexo. Porto Alegre: Sulina, 2005.

OECD. PISA 2009 results: overcoming social background - equity in learning opportunities and outcomes. Paris, 2010a. v. 2. Disponível em: <https://doi.org/10.1787/9789264091504en>. Acesso em: 29 mar. 2017.

OECD. Pisa 2009 results: what students know and can do - student performance in reading, mathematics and science. Paris, 2010b. v. 1. Disponível em: < https://doi. org/10.1787/9789264091450-en>. Acesso em: 29 mar. 2017.

RUMBERGER, R. W. Education and the reproduction of economic inequality in the United States: an empirical investigation. Economics of Education Review, Kidlington, v. 29, n. 2, p. 246-254, 2010. Disponível em: <http://dx.doi.org/10.1016/j. econedurev.2009.07.006>. Acesso em: 24 mar. 2017.

SILVA, G. O. V. Capital cultural, classe e gênero em Bourdieu. Informare, Rio de Janeiro, v. 1, n. 2, p. 24-36, 1995. Disponível em: <http://hdl.handle.net/123456789/215>. Acesso em: 24 mar. 2017.

UNITED NATIONS. Economic and Social Affairs. World population prospects: the 2008 revision: highlights. New York, 2009. (ESA/P/WP.210). Disponível em: <http://www. un.org/esa/population/publications/wpp2008/wpp2008_highlights.pdf>. Acesso em: 24 mar. 2017.

Artigo recebido em 08/03/2016. Aceito em 15/10/2016. 